Received: 19.04.2021.

doi: 10.46763/JESPT211610079k

udc: 37.018.43:004]:316.723-021.463

Revised: 01.05.2021.

Accepted: 05.05.2021

\title{
TEACHING FORMS, METHODS AND TECHNIQUES USED BY EFL TEACHERS AND THEIR INFLUENCE ON INTROVERTED STUDENTS
}

\author{
Ana Koceva ${ }^{1}$ \\ Faculty of Philology, Goce Delcev University, Stip, Macedonia \\ ana.koceva@ugd.edu.mk
}

\begin{abstract}
The forms and methods of teaching used by teachers of EFL have a direct effect over the students' learning process and their final achievements. The way that students will accept a certain teaching style depends on their own behaviour and personality as well as the teacher's ability to successfully manage and conduct the forms and methods of teaching. In this paper I define different types of forms, methods and techniques used in Secondary schools in North Macedonia, and I emphasize some that have become very widely accepted and used. Furthermore, I list some disadvantages that these popular forms, methods and techniques of teaching have over introverted students. Finally, I elaborate on the most adequate forms and methods of teaching English as a foreign language that will enable the teacher to successfully include and engage introverted students, and to be satisfy the needs of the other students as well.
\end{abstract}

Key words: introversion, teaching forms, methods, techniques, EFL.

\section{Introduction}

Teacher's teaching methods and techniques are the most important factor in the educational process. They directly influence students'learning process and determine students' future advancement in a particular subject. Therefore, the variability of methods and techniques is completely necessary in order to suit the needs of all types of students. Different types of students in the classroom means that there are individuals with different behaviour, different learning abilities, different preferences etc. All of these aspects that emphasize the importance of teachers' methods have produced a variety of methods and techniques, but some of them have gradually risen to the top and have become very popular among teachers. Unfortunately, the widely accepted popular methods and techniques eventually transformed into a highly repetitive set of methods and techniques.

Teachers of English as a foreign language in North Macedonia have always been the leaders in relation to the application of various methods and techniques as well as the new technological devices. There are two reasons for this. First, English as a subject requires teaching more than one skill to the students and it covers a long list of topics. It is practically impossible to cover reading, listening, speaking and writing with only one or even a few forms of teaching. Secondly, the comprehension of the English language itself has served as an advantage for the teachers and offered them endless methods, techniques, lesson materials, applications etc. that are available online for free. However, I do not mean that there aren't teachers of other subjects that speak English, but the content available for other subjects is incomparable with the huge quantity of materials for English. The variety of resources means variety of teaching forms and methods, but some of them have been distinguished as better by English teachers. These forms and methods of teaching offer a practice for multiple skills simultaneously and they were also widely accepted and praised by teachers around the world. The constant positive feedback led to overuse and repetitiveness, which had a very negative effect over those students that weren't comfortable or didn't respond well to these forms of teaching. The students that have difficulty for different reasons in accepting some teaching methods and techniques are often considered as failing, unsuccessful, bad at learning etc. It took a long time to change the teachers' point of view and 
the public opinion and to come to the conclusion that students' personality has a significant influence over their learning style and that some students aren't a failure or unintelligent, but they might be just shy or introverted.

In this paper I will explain some of the most often used teaching methods, forms and techniques based on the official teaching plans used in schools in North Macedonia. Also, I will define the negative aspects of these teaching forms in relation to students' different personalities and the effect that they have over introverted students. Finally, I will suggest changes that can improve teaching and help students achieve better results in English.

\section{The concept of introversion and extroversion}

The distinction between introversion and extroversion as two opposite personalities was introduced by psychologist Carl Yung. He defined introversion as "attitude-type characterised by orientation in life through subjective psychic contents", while extroversion as "an attitude-type characterised by concentration of interest on the external object" (Jung, 1995 pp. 414-5.). This view is no longer considered completely relevant, due to its complete separation of the two personalities. The contemporary widely shared view is that introversion and extroversion are two opposite ends on a single continuum. Therefore, people's personality type is expected to be somewhere in the middle, whether closer to one end or the other. Consequently, introverts and extroverts are not people with completely opposite personalities, but people with different preferences, priorities and behaviour.

Gradually, the term introversion has spread from psychological papers to the real everyday life of common people. "The Introvert Advantage" is a very practical and engaging book that offers simple and understandable explanation of the term and a lot of advice that will ease the life for any introvert. The Doctor of Psychology Marti Olsen Laney (2002) defines introversion as a type of temperament and emphasizes its difference from shyness. Furthermore, she determines the three key differences between introverts and extroverts which are energy creation, response to stimuli and approach to knowledge and experience. First, introverts are considered energy conservers, while extroverts are energy spenders. Secondly, introverts prefer less stimuli while extroverts thrive on a variety of stimuli. Thirdly, in relation to acquiring knowledge and experience, introverts focus deeply on a small number of activities, but extroverts focus on a range of topics and avoid any limitations. This last area of differentiation is especially important for teachers and professors that need to balance and satisfy the needs of all students regardless of their temperament or personality.

Another writer that stirred a lot of attention and has helped raise awareness for introverted people is Susan Cain. Cain's undeniable influence is verified by her TED talk labelled "The power of introverts" that has been viewed more than 28 million times. Also, in her book "Silence" she managed to shift the focus on the positive traits and capabilities of introverts as well as the benefits of these qualities to the world. In the third chapter, which I believe is mandatory for all teachers, S. Cain (2012) introduces a new concept that she names "the new groupthink". The new groupthink values cooperation, teamwork and open office/school plans. The strong emphasis on teamwork and collaboration has caused a wide implementation of cooperative learning and small group learning at the schools. The high level of implementation has consequently led to a negative effect on introverts. The new groupthink is defined as "a phenomenon that has the potential to stifle productivity at work and to deprive schoolchildren of the skills they'll need to achieve excellence in an increasingly competitive world". (Cain, 2012, p.226) Contrary to the claims that "collaboration kills creativity" (Cain, 2012, p.214) is the statement that "cooperative learning gives importance to cooperation as against our present educational system, which is based on competition" (Sighn and Ragawal, 2011, p.2).

Certainly, the complexity of the introversion/extroversion concept is no longer unknown or ambiguous for teachers, students or the general public. The presence of introverted learners in every classroom is undisputable. Also, the influence of introversion in various areas of the educational process cannot be ignored.

A detailed summary of the general features of introverts and extroverts are presented in the table below. 
Table 1: Introverts and extroverts. (Condon, M \& Ruth-Sahd, L., 2013, p. 505)

\begin{tabular}{|c|c|}
\hline Introverts & Extroverts \\
\hline Quiet; reticent & Talkative; confortable in the spotlight \\
\hline Reflective; introspective & Active: bighty engaged with the outside world \\
\hline Serious & Lighlo-hearted \\
\hline Think before speaking & Think wille speaking \\
\hline Reclusive & Gregaricus: outgoing \\
\hline Risk-aversive; cautious & Bold \\
\hline Uncomfortable with conflist & Assertive: dominant \\
\hline Prefer small gatherings with friends & Confortable in larger groups that include strangers \\
\hline Tentative; delaberative & Enthusiastic; make quick decisions \\
\hline Drained by the outside world; need to time spend time alone to recharge & Energized by the outside wotld; prone to boredom when alone \\
\hline
\end{tabular}

Nevertheless, the general notions on introversion and public data are not sufficient for teachers. "There is a unanimous opinion that the professional development and self-improvement of future teachers is not possible without constant comparison, analysis and critical reflection of their own experience in view of set professional standards, as well as without self-measurement of their own achievements compared to those of fellow trainees, teachers and basic mentors." (Markova, 2020, p.64). Herein, teachers need a mandatory and extensive training about students leaning toward introversion and extroversion. This will help recognize more introverted or more extroverted students quickly, and it will consequently help improve the teaching process and help students' reach the expected level of achievement.

\section{Teaching forms, methods and techniques versus introverted students}

The question that still remains unanswered is how often do teachers' pay attention to introverted students in their classroom and do they consider the students' abilities and learning style when preparing the teaching, learning and assessment processes.

Macedonian teachers are obliged to prepare daily written lesson plans that include forms of teaching, methods of teaching and techniques for both teaching and assessment regardless of the subject or the level of education. The forms, methods and techniques of teaching for a certain subject are always suggested and part of the teaching syllabus issued by the Ministry of Education and Science and the Bureau for development of Education in North Macedonia. Although the form of a lesson plan is almost unified in Macedonian schools with small variations in different schools and for different subjects, I will focus on the subject of English as a foreign language and the teaching style of English teachers in secondary education. The last teaching curriculums for English as a foreign language for students in Secondary schools have been issued in 2014, if we don't take into consideration the shortened versions issued at the end of 2020 as a result of the current pandemic.

In the first section of the lesson plan, the teacher lists all forms of teaching and marks one or more that are applicable for that lesson. The form of teaching depends on the relation between the teacher and the students, as well as the educational material. It can be frontal, individual, groupwork or work in pairs.

Frontal form of teaching has the teacher in the focus as a lead presenter of the material, while the activity of the students is minimal. Although it is useful and necessary, frontal form of teaching should be used only for one part of the lesson and for topics in relation to grammatical rules, tenses, vocabulary etc. It is considered as a passive form of teaching, but there is a possibility for improvement. If the teacher uses other techniques to rise the students' activity and limits the time of the frontal form, it will be a very effective form. Herein, the only negative aspect is the overuse of this form and its entailment of other negative behaviour by students and teachers.

The individual form of teaching puts the students in the lead role. The aim of this form of teaching is to enable the students to understand the topic and make deductions by themselves with different teaching materials and resources provided by the teacher. Although, it is completely opposite to the 
frontal form, its overuse can also have a negative effect on the learning process. Introverts' hesitant behaviour might prevent them from asking questions or asking for help, which will eventually prevent them from correctly learning the material. The formal and the individual form of teaching are both very useful, but only when used in combination with one another or with some of the other two forms.

Groupwork or teamwork is a form that is considered very effective and therefore it has become very popular. The focus in groupwork is cooperation. Cooperative learning is usually conducted by separating students into smaller groups (3-5 students), and then giving them a certain activity and instructions for it. Furthermore, each student can be given a particular role in the group. The advantages from this form are many: it creates competitiveness among students, arouses discussions, stimulates active learning and decreases emotional stress. The teacher observes the groups, follows their work and helps and guides them when needed. However, all the advantages are the logical results expected by the 'average' student. On the other hand, introverted students need a quiet place and some alone-time in order to reflect on a certain topic and produce ideas. Also, they prefer one-on-one communication and again might find it difficult to express their opinion to the other members of the group. Consequently, these students will remain silent and would not participate in the learning process at all, which leads to an unsuccessful lesson.

Work in pairs has the same focus which is cooperation, but it is more appropriate for introverts. It offers a one-on-one communication, which is more approachable for introverts and decreases any pressure or stress from them. Moreover, it allows equal participation of both students and a longer stretch of time to do their work and to actively participate in the lesson.

The second section of the lesson plan contains the applied teaching methods. Teaching methods lead the educational process and determine the role of the teacher and students, as well as the activities that will help the realization of the planned aims. There are three basic types of teaching methods: demonstrative, monologic or dialogic. As Gogoska (1995) emphasizes "the teacher must know which method will help the realization of a more successful teaching, and also to know the compatibility of the methods and the forms of teaching (p.86).

The demonstrative method involves a demonstration conducted by the teacher and uses the students' perception and their observational skills. Usually, this method is used simultaneously with another method that helps the explanation and presentation of the given topic.

The monologic method is a form of verbal presentation that puts the focus on the teacher. However, it doesn't mean that the teacher is the only active participant in the teaching process since students nor that students are passive listeners. The students are listening and pondering on the material. In order to keep the concentration and the focus of the students, the teacher needs to have a clear articulation and to speak with moderate speed. However, teachers often forget that they need to engage the students in the lesson and to allow breaks for questions throughout the lesson. Usually, the teacher stands in front of the students and explains a particular topic. Silence and order are highly emphasized, and considered as the highest achievement of the teacher for classroom management. Here, I would strongly disagree that this is the appropriate teaching and learning environment for any student, especially for introverted students. Introverts' communication style is often defined as hesitant, and they have the need to be invited in the conversation. Herein, in an environment where students feel obliged to be silent, and also afraid to share their opinion that might be different, it is natural that even more extroverted individuals would be hesitant. Therefore, teachers must change their teaching methods in a sense that the student feels free to express his/her personal opinion and to feel encouraged to ask questions. Also having in mind that there are highly introverted students, it will be useful to offer other ways of communication for example offering to answer anonymously written question in relation to the topic that is studied at the end of the lesson.

The third type is the dialogic method which involves a conversation or a discussion between the teacher and the students. It can be conducted in the following ways: a slow-paced natural conversation in relation to a given topic; asking and answering questions that stimulate the critical thinking; discussion on a given topic, problem or statements etc. The dialogical method is very important for English teachers. It helps learning and using new vocabulary, new grammatical construction and also helps the assessment of students' speaking skills. On the other hand, conversation with more than 
3 students may create an uninviting speaking environment for an introvert. Also, if assessment is combined with this method, it just amplitudes the negative feelings in introverts.

These three methods mainly focus on teaching speaking skills, which is only one part of knowing and learning a language. There are many other methods used by teachers that focus on the remaining skills which are: reading, listening and writing. I will mention those that I believe are very often used by teachers of English as a foreign language in North Macedonia.

Total physical response is a method that combines speech with physical movement. The teacher makes a speech output and students respond with a particular physical movement.

Silent way of teaching means a passive teacher and very active students. The teacher produces the right environment and encourages students to speak and deduce their own conclusions.

Grammar - translation method is one of the most used by Macedonian teachers of English and is in accordance to the activities that student's books offer. However, teachers do not label it as grammartranslation method, but put the names of the techniques that they use such as text analysis or writing. The activities involve reading comprehension, answering questions in relation to the read language, analysis on written forms, translation of paragraphs, translation of grammar rules etc.

The oral method was derived in opposition of the grammatical translation method. It is also referred to as the direct method and is based on a complete usage of the target language or in this case English. Students are encouraged to speak and think in English. The lesson topic or the aim of the lesson is described, then explained and practiced by speaking and listening of everyday situations. The grammatical rules or the vocabulary terms are being learned through demonstration and discussion.

The structural method uses similar techniques as the direct method, but it also includes reading and writing. It focuses on structures either grammatical or phraseological. It is believed that structures can be taught by creating an adequate situation. When there is an appropriate situation, students can practice particular structures by speaking or writing. The practice can be done in various ways such as adding, ordering or grading of structures, or producing similar structures or patterns. Also, it can include words, phrases or clauses and whole sentences.

The audio-lingual method of teaching is focused on repetition and memorization in order to teach listening and speaking skills. Students are expected to listen to a short dialogue or a monologue that uses a particular grammar or vocabulary. The model dialogue or monologue serves as guidance and students should repeat the key phrases, change them or produce similar speech patterns from that dialogue while the teacher corrects grammar or vocabulary and pronunciation. It is mostly used for grammar, but it doesn't include an explicit explanation of grammar and it allows only use of the target language. it is also used for learning new vocabulary through phrases or other structures, and by adding new words to a certain speech. The advantage of this method is its simplicity that makes it easy to understand and students know what is expected of them. The disadvantage is it doesn't help improve students' communication competence and is teacher-centred. Also, it is a behavioural method that relies upon a positive or a negative feedback. If a student uses the correct or the expected grammar construction or vocabulary phrase, he/she gets a positive feedback. On the other hand, the student will receive a negative feedback and if it's part of an assessment lesson, it might result in a negative grade. This particular aspect of the method creates a lot of pressure for the introverted students, which is then amplified by the lack of time that the student has to think about his/her answer.

Cooperative learning is a very frequent and praised teaching method due to its large impact on students' communicational and social skills. It is considered as highly effective, because it helps practice speaking, listening, reading and writing skills, but it also teaches cooperation that is a social skill. According to Gudinge (2018) "in cooperative learning, all student's participation is important, and in order to achieve a well-functioning group, the engagement of all students is required" (p. 9). Students are expected to cooperate to fulfil a shared goal and practice all English skills. It can be used for making a project in relation to grammar, vocabulary or any other topic. However, it is a more complex method that doesn't guarantee success. As Gilles (2016) notes "placing students in groups and expecting them to work together will not necessarily promote cooperation" (p. 4). The success of cooperative learning can be achieved by four key components proposed by Gilles (2016) and these are the following: structuring positive interdependence within the learning situation, promotive interaction of group 
members, individual accountability of one's responsibility in the group and negotiating or teaching interpersonal skills. Also, the other problem as Cain (2012) claims is that introverts have a creative advantage as a direct result from independent work and solitude is deemed as a catalyst to innovation. Therefore, cooperation decreases the creativity of introverts. This can also be overcome by using different techniques or strategies for cooperative learning that are more suitable for introverts, such as the think-pair-share strategy. As Gudinge (2018) explains, the think-pair-share strategy is conducted in four simple steps: the teacher hands out a task, students think for themselves, then students discuss in pairs and eventually they discuss and share their opinions with the group and the whole class. Herein, there is a perfect strategy that satisfies the needs of introverts to ponder and reflect on the topic or the issue, and it also allows extroverts to discuss and brainstorm within the group.

The final method that contains all of the advantages of the previous method is labelled as mixed or eclectic. The eclectic method is "a language teaching method that combines various approaches and methods to teach language depending on the objectives of the course and the abilities of the learners" (Iscan, 2017, page 3). This is the key method that can help EFL teachers create lessons that suit the needs of every student, and at the same time prevent any disinterest or reluctance for participation by all of the students.

In the third and fourth section of the teaching plans, teachers name the teaching resources and materials, and sometimes even the techniques used for the realization of the lesson. Teaching resources can be: auditive, visual, audio-visual and material. Naturally, they help the teacher prepare faster and better for the lesson. All of these resources are necessary in teaching English. The auditive and audiovisual resources help improve students' listening skills, and the written resources help reading and writing skills. However, the successful realization of the teacher's plan and the syllabus depends solely on teachers and their ability to successfully combine the teaching form, the method and the resources and then to successfully implement them in the lesson.

The techniques used for the realization of the lesson best describe the chosen combination of forms and methods. Some of the most frequent are the following: presentations, brainstorming, interviews, interactive exercises, projects, discussions, writing and reading on a given topic etc. These are popular and efficient techniques, but teachers need to adapt them for the introverted students in the classroom. If a student needs to make a presentation, the teacher can offer it to be done in pairs or to offer the student to present from his usual place of sitting. For brainstorming, teachers can propose written ideas as well as speaking. Also, introverted students will need more time to think about a given topic, therefore the teacher can allow a certain time limit of thinking before sharing thoughts and ideas. All the other techniques that offer speaking can be improved by giving a time limit, offering students to respond from their usual seat even without standing up, and always to offer a choice of working alone or working in pairs. These small changes to the contemporary and successful techniques will have a strong positive impact for students closer to the introverted side of the continuum.

\section{Conclusion}

Introversion and introverts have been recognized in society, and therefore they should be recognized as ordinary students in the classroom. Teachers of English as a foreign language need to be aware of the constant presence of introverted students in the classroom. Therefore, their choice of a form, method and technique for teaching should be applicable to all students. In order to ensure success for every lesson, teachers have to always use an eclectic method of teaching with a combination of different forms and techniques. This is very easy for English teachers, since the contemporary coursebooks offer smaller unit chapters that include all of the skills (listening, reading, speaking, writing) needed to learn English. From my personal experience the best way to achieve the aim of the lesson and to keep the students' constant interest is to use a combination of methods and techniques, to divide the lesson in a group of smaller lessons that will cover all the skills. There isn't a negative form, method nor a technique, but only an inadequate way of conduct or a combination done by the teacher. In conclusion, my advice for all teachers is to look at their class as a small society filled with diversity of personalities, behaviours and talents, and keep your teaching style as divertive and eclectic. The main conclusions of the study may be presented in a short Conclusions section, which may stand alone or form a subsection 
of a Discussion or Results and Discussion section. Conclusions should provide a summary of important findings and their implicants to the area of research that is the forms of the article.

\section{References}

Cain, Susan. (2012). Quiet : the power of introverts in a world that can't stop talking. New York: Random House, Inc.

Condon, M \& Ruth-Sahd, L. (2013). Responding to introverted students: Best practice guidelines for educators and advisors. Open journal of Nursing, 3, 503-515. http://dx.doi.org/10.4236/ ojn.2013.37069

Jung, Carl (1995). Memories, Dreams, Reflections, London: Fontana Press.

Gogoska, L. (1995). Didaktika. [Didactics] Skopje: Zvezda.

Gilles, R. M. (2016). Cooperative Learning: Review of Research and Practice. Australian Journal of

Teacher Education, 41(3), 39-54. http://dx.doi.org/10.14221/ajte.2016v41n3.3

Gudinge,m J. (2018). Cooperative Learning: A teacher Perspective. [Degree project]. Malmo: Malmo

University Electronic Publishing. https://muep.mau.se/handle/2043/25027

Iscan, A. (2017). The Use of Eclectic Method in Teaching Turkish to Foreign Students. Journal of Education and Practice, 8 (7), 149-153. https://eric.ed.gov/?id=EJ1137580

Laney, M. O. (2002). The introvert advantage: How to thrive in an extrovert world. Workman Publishing.

Singh, Y.P., Agrawal, A. (2011). Introduction to co-operative learning. Indian Streams Research Journal, 1 (2), 1-9. https://www.researchgate.net/publication/270494960 INTRODUCTION TO COOPERATIVE LEARNING

Smith, J. Guimond, F-A., Bergeron, J., St-Amand, J., Fitzpatrick, C., Gagnon, M. (2021). Changes in Students'Achievement Motivation in the Context of the COVID-19 Pandemic: A Function of Extraversion/ Introversion? Education Sciences. 11 (30), 1-8. https://doi.org/10.3390/educsci11010030

Markova, Z. (2020). Future EFL Teachers' attitudes toward self-assessment. Orbis Linguarum, 18, (2). 64-72. https://doi.org/10.37708/ezs.swu.v18i2.8 